\title{
Never, Ever Break Up a Family*
}

\author{
Steven William Schaufele \\ Soochow University, Taipei, Taiwan
}

\begin{abstract}
Speculative-fiction stories, in print, often depict families being wrenched apart by overwhelming new forces to which the children are better able to adapt then older generations. In making speculative-fiction movies, however, Hollywood typically offers a more hopeful, comforting image of a family, at the beginning somewhat less than perfect, being restored as a result of those same forces. This paper concentrates on The Spiderwick Chronicles (2003-2004) by Tony DiTerlizzi and Holly Black, Susan Cooper's novel The Dark is Rising (1973), and Lewis Padgett's story "Mimsy were the Borogoves" and the recent movies based (more or less loosely) thereon, Mark Waters’ The Spiderwick Chronicles (2007), David Cunningham's The Seeker (2007), and Bob Shaye's The Last Mimzy (2007), showing how the differences between the movies and the print-stories they are based on reflect an attempt on the part of the movie-makers to reaffirm and reinforce the family bonds that are to some extent sundered in the original stories.
\end{abstract}

Keywords: speculative fiction, printed matter, movies, movies based on printed matter, damaged families, adaptation to screen

\section{Introduction}

\section{Childhood's End}

In Clarke's novel Childhood's End (1953), the human race is subjected to subtle encouragement to evolve past the level of individual existence into a communal level where what had heretofore been separate individuals become merely parts of a larger whole. The title refers at once to the end of human childhood in the traditional sense and to the end of the "childhood" of the human species, as that species-in and through its children — evolves onward to which some might consider a "higher" form of life, though it is very much an open question as to whether the author so regards it. It is perhaps worth noting that throughout the novel, children are shown as more ready to accept radically new things and ideas; for instance, they are more willing to accept the "Overseers”, in spite of their “diabolical” appearance.

In the last part of the novel, the adults watch helplessly as their children take this route, in the process abandoning them and, seemingly, everything that in terms of patterns of thought, etc., had heretofore been considered "human". It is implied that, in the end, the "family" as it has traditionally been regarded—as a suitable context in which to carry on the species-has outlived its usefulness, and must now die a natural death.

\footnotetext{
${ }^{*}$ An earlier version of this paper was presented 17 November, 2012 at the Children in the Book TCLRA Conference at Soochow University in Taipei.

Steven William Schaufele, Ph.D., assistant professor, Department of English Language and Literature, Soochow University.
} 
E.T.

In Spielberg's movie E.T.: The Extraterrestrial (1982), we are presented with a family unit consisting of a single mother and three children, ranging in age from adolescence to kindergarten; it is undoubtedly of some at least subliminal significance that this is a damaged family - the father has left them, run off with his secretary, in the process violating at least one of the mother’s supposedly well-founded beliefs about him (“He hates Mexico!”). Of the four members of this family, the movie concentrates on Elliott, the middle child, who is able to build a poignantly close relationship with the stranded alien explorer who is the title character. In the process, Elliott encounters some initial friction with his siblings Michael and Gertie, but this is overcome fairly quickly; much greater friction occurs between the children and their mother, who learns of E.T.'s existence only minutes before their home is invaded by a different sort of alien: adults from outside the Family who seem to be intent only on wresting as much scientific and technological data as possible from E.T. before hann dies_-and, if possible, from Elliott as well.

In the end, however, E.T. is reunited with his own people, and likewise Elliott and his siblings manage to make an ally of their mother-and, along the way, connect also with Keys, a male member of the "invading” research team, who confesses to Elliott a great deal of sympathy with his situation; it is at least implied that Keys may eventually become a new father to Elliott and his siblings.

In short, in the printed novel Childhood's End, the "traditional” family, having outlived its usefulness, dies a natural death. In the movie E. T., on the other hand, the family is repaired; just as the title alien at the end is restored to hanns own kind and is able to "go home", so Elliott's family is stronger and healthier in the end than at the beginning.

The main point of this paper is that the demise, the falling apart of a family is more easily presented in a printed story or book than in a Hollywood movie. The Hollywood movie industry is geared much more heavily towards the strengthening, the restoration, and the reparation of family bonds. While in a printed story, we are more likely to encounter a family that at least on the surface seems strong and healthy at first, but from which the protagonist, in various ways, must in the course of the story take flight, in a Hollywood movie we are apt to find a family that, at the beginning of the story, is defective in some way, but during the course of the movie is healed, resored, strengthened, and the protagonist's growth is represented by hanns return to the family from which hanns originally came.

This paper will focus on three recent speculative-fiction movies ${ }^{1}$, Mark Waters’ The Spiderwick Chronicles (2007), David Cunningham's The Seeker: the Dark is Rising (2007), and Bob Shaye’s The Last Mimzy (2007), that differ to varying degrees in this regard (among others) from their respective print-sources, Tony DiTerlizzi and Holly Black’s book The Spiderwick Chronicles (2003-2004), ${ }^{2}$ Susan Cooper's novel The Dark is Rising (1973) and Lewis Padgett’s short story “Mimsy Were the Borogoves” (1943).

\footnotetext{
1 "Speculative fiction" is being used here as a sort of umbrella-term that includes both "fantasy" and "science fiction" in its reference, obviating any need to choose between those two labels.

2 The "book" is actually marketed as five small volumes, each just a little over 100 pages long, and furthermore heavily illustrated-DiTerlizzi, whose name is given on the title pages ahead of Black's, is actually the illustrator, while Black is the author - but it is quite clear to anyone who bothers to read them that these five volumes represent a single story.
} 


\section{Spiderwick Chronicles}

As presented in DiTerlizzi and Black’s (2003-2004) book, the Graces are a family with problems. For one thing, the parents, Helen and Richard, are divorced, and indeed Richard never really appears at all in the story. ${ }^{3}$ For another, Jared, the point-of-view character, one of a pair of twins who together are the younger of the three Grace children, has “anger issues”, a temper that, at the age of nine, he has a great deal of difficulty controlling and that frequently gets him into trouble.

In Waters' movie, some of these problems are actually exaggerated. While, at a couple of focal points, Jared expresses great anger at one or another of the other characters, his "anger issues" are to a great extent played down; unlike in the book, the viewer of the movie has little sense of a deep pit of anger simmering more or less constantly under Jared's surface. However, the divorce between Helen and Richard brings with it-in the movie - a fair amount of tension, leading in some cases to open arguments and fights, between the children and their mother, and perhaps also between the children and each other. Jared in particular longs for his father to return and "rescue" him from his current situation, and seems to be more or less deliberately resisting any complete understanding of what the divorce really means. Whereas, in the book, the divorce is established quite early as a fait accompli that all parties, including the nine-year-old twins, merely accept as an unfortunate fact, in the movie Jared has to have it "broken” to him fairly late in the story, by his 13-year-old sister, that Daddy is not, repeat not, coming back.

These details provide the essential background leading up to the climax (quite different in many details from what is presented in the book) in which Helen and her three children have to battle side-by-side to protect themselves, their house, and Helen's great-uncle Arthur Spiderwick's field guide to the fantastical world around you from the ogre Mulgarath. In the book, the battle against Mulgarath is carried out primarily by Jared; in the movie, the battle in which Helen and the children struggle side-by-side binds the four of them together powerfully, so that, by the end of the movie, the viewer has a very strong sense that the family, as damaged as it has been, is prepared to make a serious go of it. Although the book ends with some hopeful assurances that things are going to work out, such a strong sense of renewed mutual commitment is lacking.

A relatively minor detail that seems relevant to the issue central to this paper concerns Hogsqueal the hobgoblin. In the movie, Hogsqueal explains his vengeful ire against Mulgarath by saying that Mulgarath is responsible for the annihilation of Hogsqueal's family. Granted, Hogsqueal is by nature a boastful preener most of whose statements have to be doubted at least to some extent; on the other hand, nowhere in the movie are we offered any evidence contradicting his claim that in resolutely opposing Mulgarath he is seeking to avenge his family. This family motivation seems to have been brought in for the movie; there is nothing about it in the book.

Meanwhile, in the book Helen’s aunt Lucinda Spiderwick expresses grave doubts about her father Arthur's love for her, and is extremely surprised to find the portraits of her that he has drawn and painted; as far as she could tell, he just wandered away, some 80 years earlier, selfishly intented upon his research and completely forgetting about his family, and has never returned. Whereas in the movie it is clear that Arthur Spiderwick, at the time he is "taken away", is desperately fighting to protect his daughter's life-in her presence, so it seems to be clear to her as well as to the viewer. At the very end of the book, Arthur Spiderwick dies in his daughter's arms. At

\footnotetext{
${ }^{3}$ He is at one point “impersonated” by the villain, Mulgarath.
} 
the end of the movie, however, he does not die; still supported physically by the fairies who protect him from his own mortality, he "walks away", hand in hand with his daughter-who has herself been restored to the age of an elementary-school-age girl, as she was the last time she saw him.

\section{Seeker}

In Susan Cooper's Newbery-Honor-winning novel The Dark is Rising ${ }^{4}$, Will Stanton is the youngest of 10 children born into a family that has apparently been living in Huntingdonshire, England, for generations; the story takes place around Will's 11th birthday, which occurs in December, just a few days before Christmas. In the course of the book, Will learns of the existence of the "Old Ones", a group of godlike beings who are the "good guys" in this story, and that he is in fact the last of the 'Old Ones' to be born and to come into his powers, along the way recovering six "Signs" that together give the Old Ones the means of overcoming the threat of "Darkness" = Evil taking over the world. At a certain level, the story is primarily about Will's maturation, over the course of a few weeks, from a fairly ordinary pre-adolescent into someone with at least the raw potential to become a godlike being.

It was mentioned above that, in the book, Will is the youngest of 10 children. During the course of the story, however, he learns that there was, in a sense, an 11th-Tom, the first son of Roger and Alice Stanton, who died young of a respiratory ailment. In David Cunningham's movie The Seeker: the Dark is Rising, there is also a "missing" son, ${ }^{5}$ but in this case the missing brother (also named Tom) is Will's twin. Perhaps more importantly, in the movie Tom is still living; he has merely been kidnapped by the "Dark", the Forces of Evil; his recovery \& restoration to his family at the end of the movie is the ultimate sign of that family's own recovery and restoration. ${ }^{6}$

\section{Strife Within Stanton Family in Movie}

In the book, the Stantons have been living in this area of Huntingdonshire for generations. In the movie, they are American expats, recently arrived, struggling to settle in. ${ }^{7}$ In the book, Will's father Roger is a jeweler; in the movie, his name is "John", and he is an academic — a scientist and college professor; moreover, it is indicated that he's in some professional/financial trouble, that his current (short-term?) appointment to a British university is, from his point of view, a desperate gamble to save his career.

In the book, the Stantons are presented as a fairly normal, healthy family; there is a certain amount of the kind of teasing that goes on in such a family, but underneath that very thin surface friction there is a very strong bond of love binding the family together, providing Will with the wholesome background from which he has to graduate. In the movie, there is quite a bit more tension; Robin and Paul pick on Will a lot more than anybody does in the

\footnotetext{
${ }^{4}$ Actually the second volume of a series of five books, for which "The Dark is Rising” also serves as a kind of general umbrella-title.

${ }^{5}$ In both book and movie, it is apparently of some importance that Will be a "7th son", but that he should be unaware of the fact until sometime in the midst of the actual story.

${ }^{6}$ Probably to underline the point further, when Will at the end of the movie returns home with Tom, it is spring —even though it's winter just a little bit earlier.

7 There seems to be no reason for the Stantons being redefined as a family of American expats who have recently moved to England; is the story somehow more believable, or more accessible, when told of such expats than it would be of plain old English people who have been living in the same area for generations? Did Cunningham imagine that he could not get real British actors to play the relevant parts, or, if he was absolutely wedded to a certain American actor or group of actors, was he unwilling to hire a "dialect coach" to get those American actors to speak with decent, believable English accents? The people responsible for the Twilight (2008) movies and Remember Me (2010) seem to have had no problem hiring a dialect coach to get Robert Pattinson to sound like a Yank onscreen.
} 
book; Max, struggling to hide the manifold difficulties he is having in college, is rather belligerent; and John, the father, is rather distant, apparently to some extent consumed with guilt over the loss of Will's twin brother Tom. In short, in the movie the Stantons are a family very much in need of healing, and Will effects that healing, partly by pressing his brother Max towards a healthier perspective on his problems, most importantly by bringing his new-found twin brother back to the bosom of the family.

\section{Maggie Barnes}

Early in the story—a few days before Christmas-Will has a birthday. In the book, it is explicitly stated that this is his 11th birthday; in the movie, it is equally explicitly stated that this is his 14th. Why this (apparently gratuitous) is different? The only apparent rationale for it is Maggie Barnes, a stooge of the Dark. In the book, Maggie is a very minor character: She is the dairymaid for the Dawsons, a neighbouring family, and is sweet on Will's brother Max (who does not return the feeling, being romantically involved with one his college classmates). Although such a minor character would be easily expendable in the movie, ${ }^{8}$ in fact, it is beefed up; in the movie, Maggie is a student at the same school Will is attending; she is "going out" with Will's brother James, while doing her best to seduce Will. Making Will a 14-year-old adolescent presumably makes it possible for him to have at least an incipient erotic interest in Maggie-more so than would be the case for Cooper's 11-year-old Will. Which in turn provides opportunities for Will to display the usual sorts of adolescent angst, which would be totally out of place in Cooper's conception but which presumably, by providing a handle of commonality makes the whole story more accessible to the ordinary, run-of-the-mill audience.

\section{Godlike “Old One” or Adolescent Superhero}

\section{“Mental” vs. "Showy" Powers}

In the book, a lot more emphasis is placed on Will's purely mental powers. At one point, he wipes an incident from another person's memory; more importantly, while in the movie Will is full of questions, with which he pesters Merriman and Miss Greythorne, in the book he frequently guesses at the answers-and guesses correctly. He evinces a nearly godlike, or at least metahuman, intuition.

Such pure mental powers are probably easier to depict in a book, something meant to be read; the "showier" powers that Cunningham's Will manifests are doubtless more satisfyingly presented in the visual medium of a movie. But—as is evidenced by, among other things, certain scenes in The Last Mimzy ${ }^{9}$ —more "mental” powers can be satisfyingly presented in this visual medium.

\section{Which Is More Important}

Which is more important, Will Stanton or the Signs that he has to collect? In the movie, the focus tends to be on the Signs themselves - the physical objects, ${ }^{10}$ and Will's importance seems to be primarily that he is the one person who can find all of them. This may be at least part of the reason for the change in title: In the movie, Will

\footnotetext{
${ }^{8}$ Like three of Will's sisters. While for someone writing a story that is to be read adding extra characters costs only a little bit extra ink, actors cost money, and extra actors cost extra money, so, since Will's four sisters are not essential to the plot, it makes sense that in the movie they are reduced to one-and that one is redefined as being younger than Will, thereby making it feasible for him to adopt a protective attitude toward her.

${ }^{9}$ For instance, at one point Scott with just his mind moves a can of soda from the porch on which he is sitting to a table out on the lawn; at another, we see him, as if in a dream, building a sort of interplanetary bridge.

${ }_{10}$ Well, most of them are physical objects. In the movie, the Sixth and Last Sign is explicitly described as "the Sign that cannot be found because it was never hidden”, and identified as Will's own soul.
} 
is explicitly defined as "the Seeker", important primarily for the purpose of finding the six Signs which, once they are brought together, will assure the Old Ones' victory over the Dark. In the book, the Signs are important, but represent only a (small) part of the total importance that is vested in the person of Will Stanton. At a fairly early stage in the story —in the book —one of the Old Ones says to Will, "He is chasing you. I'm afraid the guess that is in your mind is right, Will. It isn’t the sign they want most of all. It’s you” (Cooper, 1973, p. 37).

The Signs are not quite the same in the book and the movie. The order in which Will gains possession of the Signs, and the details of where he does so, differ significantly between the two sources. Perhaps more importantly, while in the book each Sign comes from a different era, ${ }^{11}$ in the movie they were all crafted at one time, by one person—Will's mediæval ancestor Thomas Stanton.

\section{Immortal or Superhero}

Which leads to the last, and perhaps most important, question raised in this paper in connection with Cunningham's adaptation of Cooper's story. In the book, the "Old Ones"- the good guys, the leaders of the struggle to save the world from the powers of darkness, the gang whom Will joins_-are explicitly defined as being immortal. Merriman Lyon, who is sort of Will's tutor throughout the story, is identified with the Arthurian figure of Merlin, meaning among other things that he has lived well over 1,000 years. ${ }^{12}$ But in the movie, we are told that this mediæval ancestor of Will's, Thomas Stanton, who fashioned the Signs, was himself an Old One-yet he has, apparently, died in the normal way, and at a certain point Miss Greythorne exhibits his grave to the (modern) Stantons.

So what are the Old Ones? What is it, exactly, that Will is turning into? In the movie, it is essentially a superhero $^{13}$ — a person with a few significantly unusual abilities, ${ }^{14}$ but basically just a human being —a human being an important part of whose triumph, at the end, is to be able to restore his long-lost twin brother to his family. In the book, it is rather more than that. As an "Old One", he is effectively immortal-he will, presumably, continue to advance to adulthood, but once he gets there, if he ages at all it will be extremely slowly; with his god-like intuition, he has what appears to be nearly unlimited direct access to information; and, as an immortal, his family becomes in the end little more than the wholesome background that, like a good school, he may cherish but from which he must eventually graduate.

There are plenty of depictions, in movies and in other media, of adolescent boys; there are quite a few depictions of superheroes, and of adolescents turning into superheroes. There are far fewer depictions of newly-born gods, of humans turning into gods. Which do we need more of?

\section{Cinematic Opportunities Ignored}

The book contains several scenes that are told better through the use of "language" in the usual sense of the word, while the movie instead contains scenes that are presented more effectively via a visual medium. But it is not as

\footnotetext{
${ }^{11}$ Furthermore, the Sign of Wood needs to be ritually refashioned roughly every 100 years, since it's made of rowan-wood that will not last through the ages the way, say, oak will.

${ }^{12}$ And, since the Old Ones are routinely able to travel freely through time, it is at least strongly implied that Merriman has lived through at least some of those intervening centuries more than once.

13 Although at one point Will explicitly denies this label, presumably because at least at that moment-in which he is experiencing a certain amount of frustration - he does not see himself as fitting his adolescent image of what a superhero is supposed to be.

${ }^{14}$ He is able, whenever necessary, to "summon great physical strength”; to command fire and light; to move objects with his mind; to travel freely through time.
} 
simple as that; Cooper was a writer, not a movie-maker, and there are times in her story when she seems to be struggling to describe with words what, perhaps, could be more satisfyingly presented visually. Early in the story, there is one such sequence that takes up two whole chapters. Allow a few sentences to be quoted:

He was woken by music. It beckoned him, lilting and insistent; delicate music, played by delicate instruments that he could not identify, with one rippling, bell-like phrase running through it in a gold thread of delight. There was in this music so much of the deepest enchantment of all his dreams and imaginings that he woke smiling in pure happiness at this sound. ... In that flash, everything had changed. The snow was there as it had been a moment before, but not piled now on roofs or stretching flat over lawns and fields. There were no roofs, there were no fields. There were only trees. Will was looking over a great white forest: a forest of massive trees, sturdy as towers and ancient as rock. They were bare of leaves, clad only in the deep snow that lay untouched along every branch, each smallest twig. ... He was crystal-clear awake, in a Midwinter Day that had been waiting for him to wake into it since the day he had been born, and, he somehow know, for centuries before that. Tomorrow will be beyond imagining. (Cooper, 1973, pp. 20-22)

There are several scenes in the book that, in the author's opinion, are crying out for cinematic treatment-yet Cunningham includes none of them in his movie. The movie does include some rather eerie scenes, but none of them are anywhere near as strikingly supernatural as are several of the scenes in the book. In short, the Cunningham movie is a disappointment. It is OK as it stands-it is fun, if you have not read the book. But if you have, then you know that there are so many ways in which it could have been a much better movie.

\section{Mimszy}

In Lewis Padgett's ${ }^{15}$ story “Mimsy were the Borogoves”, Scott Paradine, aged seven, gains access to a bunch of "educational toys", which he shares with his two-year-old sister Emma. These “educational toys” teach the children a variety of skills, relating among other things to the ability to travel through some higher dimension that our unaided human senses cannot naturally perceive. It is clearly stated in the story that Scott and Emma are able to learn these skills because they, their minds are young, flexible, malleable — they have not "been conditioned to Euclid”, as the story puts it-and furthermore, that Emma is more successful at this than Scott, presumably because she is younger; there are some things that Scott is able to learn only with Emma's help. The story is told mostly from the point of view of the father, who, after being introduced with the given name "Dennis", is identified only by his family name "Paradine"; several times during the story, he admits that he is completely stumped by the toys, and the associated concepts, that his children find so fascinating.

At a certain point, Scott brings up the subject of salmon, who after being born in mountain streams swam down to the ocean where they spend their whole lives, returning to their origins only at the very end, to spawn and die. In discussing this with his father, Scott enthusiastically declares that this is the "right" way to live, and expectantly raises the question: Where is the “ocean” to which he, Scott, can go to live out his life, and how can he get there? Dennis, of course, cannot answer this question-humans, after all, are not salmon-but Scott and Emma eventually manage to find the answer for themselves and, by outgrabing the momeraths, ${ }^{16}$ enthusiastically

\footnotetext{
15 The name "Lewis Padgett" is used here for short-hand convenience. "Lewis Padgett" is a pseudonym, and unlike "Mark Twain" it is not a pseudonym for a single person; "Lewis Padgett" is a married couple, Henry Kuttner and Catherine L. Moore, each of whom was a talented author of speculative fiction in hanns own right, but who, after they got married in 1940, often wrote stories together; many of those stories were then published under the name 'Lewis Padgett'.

${ }_{16}$ The story declares that the opening stanza of Lewis Carroll’s "Jabberwocky" is, in fact, a detailed description of the process whereby it is possible to travel through the 4th or 5th or whatever dimension — but that, in order to correctly read and understand that description, one has to be able to apprehend it with a truly open mind, a mind that has not been "conditioned to Euclid".
} 
walk away in a direction which Dennis cannot even see, let alone follow, although they do it right before his eyes.

It was mentioned earlier that the main POV character (Dennis Paradine) character in this story is the father; part of what this means is that we, the readers, at the end of the story are confronted with the full force of his distress at the sight of his own young children joyfully walking away from him in a direction he can neither see nor understand:

Emma’s faint voice squealed with excitement. Paradine grimaced. What the devil was going on upstairs?

Scott shrieked, "Look out! This way!”

Paradine, his mouth working, his nerves ridiculously tense, raced up the stairs. The door of Scott's room was open.

The children were vanishing.

They went in fragments, like thick smoke in a wind, or like movement in a distorting mirror. Hand in hand they went, in a direction Paradine could not understand, and as he blinked there on the threshold, they were gone.

"Emma!" he said, dry-throated. "Scotty!"

On the carpet lay a pattern of markers, pebbles, an iron ring-junk. A random pattern. A crumpled sheet of paper blew toward Paradine.

He picked it up automatically.

“Kids. Where are you? Don’t hide-Emma! SCOTTY!”

Paradine looked at the paper he held.

It was a leaf torn from a book. There were interlineations and marginal notes, in Emma's meaningless scrawl. A stanza of verse had been so underlined and scribbled over that it was almost illegible, but Paradine was thoroughly familiar with Through the Looking Glass. His memory gave him the words-

'Twas brillig, and the slithy toves

Did gyre and gimbel in the wabe.

All mimsy were the borogoves,

And the mome raths outgrabe.

Idiotically he thought: Humpty Dumpty explained it. A wabe is the plot of grass around a sundial. A sundial. Time — It has something to do with time. A long time ago Scotty asked me what a wabe was. Symbolism.

'Twas brillig-

A perfect mathematical formula, giving all the conditions, in symbolism the children had finally understood. The junk on the floor. The toves had to be made slithy [...] and they had to be placed in a certain relationship, so that they'd gyre and gimbel.

Lunacy!

But it had not been lunacy to Emma and Scott. They thought differently. Those notes Emma had made on the page — she'd translated Carroll's words into symbols both she and Scott could understand.

The random factor had made sense to the children. They had fulfilled the conditions of the time-space equation. And the mome raths outgrabe-

Paradine made a rather ghastly little sound, deep in his throat. He looked at the crazy pattern on the carpet. If he could follow it, as the kids had done-But he couldn't. The pattern was senseless. The random factor defeated him. He was conditioned to Euclid. (Padgett, 1943, pp. 258-259)

It is, perhaps, significant that after being introduced early in the story the father is referred to only by his family name; after all, it is his family that is being torn apart; it is his children who are so joyfully walking away, presumably never to return. Like the parents in Childhood's End, all he can do is stand on the shore, watching uncomprehendingly as his children blithely go off into this Brave New World into which he cannot follow them.

It is a powerful story, and, over the years, several filmmakers have considered trying to make a movie out of it. But it is significant that, when one finally succeeded in doing so, the story went through a lot of changes; Shaye's movie went through 12 years of preparation, and its script went through several rewrites, by several different people. In the end, the title was changed; the children were aged three-four years; this change is probably 
related to a great extent the realities of casting; it is undoubtedly quite a bit easier to get a six-year-old than a two-year-old to play the part of Emma. It is also worth noting, however, that whereas in the Padgett story the children actually run away - and, in order for that to happen, it must be young enough not to be "conditioned to Euclid"-in Shaye's movie no such element is present; in the movie, it is also important that Emma be able to express herself in decently-articulated English. ${ }^{17}$ Almost all the character's names were changed (the little girl, Emma, keeps her given name, but the family name is changed to "Wilder”, her brother is renamed "Noah”, and the parents are renamed "David” and “Jo" instead of "Dennis" and "Jane”-it may be noteworthy that they keep the same first initials); Dr. Holloway, the child psychologist in the Padgett story, has been split into two characters in the movie, Larry White the science teacher and Ernie Rose the neurologist; several characters are added who are not in the Padgett story at all. ${ }^{18}$ Most importantly, the plot is radically changed.

In the Padgett story, the Paradines are presented as a fairly conventional mid-20th-century middle-class American family; apart from the parents' (understandable) failure to understand what the strange toys from the far future are teaching their children and their consequent anxiety about their presence in their lives, there seems to be nothing remarkable about them; the implication is that Kuttner and Moore intended them to a kind of "Everyman" couple, in their ordinariness representative of whatever their readers regarded as Ordinary. ${ }^{19}$ In Bob Shaye's The Last Mimzy, it is at least implied that the Wilders are a family with some problems; in particular, there is some friction between the father's job and his concern about his family, and some consequent friction between him and his wife; at a certain point in the movie, he takes an extended leave from his job in order to be able to spend more time with his family, and his wife expresses strong gratitude for this decision.

The movie also, more than the story, dramatizes the children's discoveries. In the movie, Emma at one point demonstrates one of these for her baby-sitter (a character completely absent from Padgett's story), who freaks out. Eventually, the entire family is taken into custody by the FBI because of a regional power-failure directly related to the shenanigans of some of the "toys", with the result that the kids now have to struggle to explain things to the Authorities.

One of the leading differences between the print and movie versions of this story is the treatment of the far-future scientist Unthahorsten. In the Padgett story, the “educational toys” that teach Scott and Emma the wonderful skills that they then exploit at the end are, at the beginning of the story, little more than “junk". Unthahorsten is a scientist in the far future who has developed a time-machine, and wishes to test it; in order to do so, he grabs some random stuff out of a cupboard—-toys that belonged to his son, but which the son has long since outgrown - and throws them into the machine; it is not important to him what they are, only that they are matter, with mass, that can be put in the machine and sent to whatever other time he has in mind. He does this twice; in one case, the "toys" end up in 19th-century England, in the hands of Alice Pleasance Liddell, and through her of her family's friend Charles Dodgson, known to the world as “Lewis Carroll”, the author, most importantly, of "Jabberwocky"; in the other case, they end up in the USA in the 20th century, in the hands of Scott and Emma Paradine.

\footnotetext{
17 Such considerations cannot, however, apply to The Dark is Rising.

${ }^{18}$ While in many cases they may seem trivial, the changes in names, cast-list, etc. must have involved some deliberate decisions on the part of the people responsible; though explanations thereof are so far not forthcoming.

19 Although the surname "Paradine" is definitely unusual, and perhaps deserving of an explanation.
} 
In Bob Shaye's movie, on the other hand, the (unnamed) far-future scientist is not particularly interested in testing a time-travel machine; instead, he is desperately trying to recover, from a significantly earlier era, some samples of human DNA, uncorrupted by the pollutants that have so thoroughly infected his own time, in order to repair the DNA of his contemporaries. Therefore, he very carefully designs the items he sends back, in order that they may collect these samples and bring them back to him. ${ }^{20}$ At a crucial point in the story, the bunny-rabbit which Emma calls "Mimzy" absorbs some of her tears, thereby acquiring the needed DNA samples; meanwhile, the other "toys" have gradually morphed themselves into a machine that—hopefully—will send "Mimzy” back to its time of origin. The crisis comes when the system designed to send "Mimzy" back inadvertently also "grabs hold” of Emma, and almost sends her also into the far future (or rips her to atomic shreds; it is a little unclear which is liable to happen to her, under the circumstances); at this point, it is necessary for her brother and her parents, working together, to pull her back. In the end, Unthahorsten ${ }^{21}$ gets the samples that he so desperately needs, and his world is saved; meanwhile, all four of the Wilders manage to stay on Puget Sound, at the dawn of the 21st century (though Emma experiences some grief over the loss of her beloved Mimzy).

While the movie is told primarily from the children's point of view, the Padgett story focuses much more on the father. With the result, among other things, that at the end we feel the full force of the father's distress/despair at the sight of his children literally walking out on him—in a direction he cannot even see, cannot understand, much less follow.

Another, rather substantive difference has to do with agenda: In the Padgett story, the main point is discovery of super-Euclidean skills by children whose minds have not been "conditioned to Euclid", and the necessary contrast with their parents' inability to even comprehend these skills. In the movie, it is poisoning by pollutants and resultant mutation and damage to DNA.

It is of some importance that in both the Padgett story and the Shaye movie young children are involved, but the significance is different. In the Padgett story, what is critical is that the children be young enough not to have been "conditioned to Euclid", i.e., have their minds, their imaginations limited to what our own civilization takes for granted as "normal”, and are therefore intellectually flexible enough to learn the skills necessary to e.g. walk through the fourth dimension. In Shaye's movie, what's critical is the assumption that children-young children—are "innocent”, in particular that their DNA is "pure”, have not been "tampered with" by the pollutants present in our environment.

In short, whereas in the Padgett story the focus is on the difference between the children and their parents, in the movie the focus is on something that all humans (are supposed to) have in common-and the rescue of that commonality, which in the end requires some heroic acts on the part of several people, most importantly the children.

In the end, it seems to be more correct to say that Shaye's movie is "inspired by" rather than "based on" the Padgett story; Shaye's movie is telling a fundamentally different story that merely has a few (granted, important) points in common with the one told by Kuttner and Moore. Which in and of itself is a good reason for the change in title.

\footnotetext{
${ }^{20}$ It is asserted that he has tried to do something like this on several previous occasions, all of which so far have failed. This one, the one featured in this story, represents his last, desperate attempt; hence the word 'last' in the title of the movie.

${ }^{21}$ Although, as indicated, the character in the Shaye movie is unnamed, since he corresponds to Unthahorsten in the Padgett story i'll take the liberty of referring to him by the same name.
} 


\section{Conclusions}

DiTerlizzi and Black's Spiderwick Chronicles depicts a family that has problems, but-except insofar as those problems (the divorce between Helen and Richard, Jared's “anger issues”) are essential to the plot—not much is made of them; they are treated more as background, establishing the Graces as a fairly "ordinary" family. In Mark Waters' movie, on the other hand, they are magnified; there is much greater friction between Helen and her children, and among the children themselves — while, at the climax, the four of them must fight side-by-side, in the process greatly strengthening the bonds between them. Meanwhile, the breach between Arthur and Lucile Spiderwick is healed to a much greater extent in the movie than in the book(s).

In Susan Cooper's book The Dark is Rising, the Stantons are presented as a sturdy, wholesome family that provides Will, their youngest member, with a reliable, loving base from which he is able to take wing. As the story progresses, they fade into the background, the plot focussing more and more specifically on Will. In David Cunningham's movie The Seeker, on the other hand, the Stantons are presented as a fundamentally troubled family, and it is a significant part of Will's heroic achievement that he is able, in some fashion, to some extent, to heal and restore this troubled family of his.

In Moore \& Kuttner's printed story “Mimsy Were the Borogoves”, Scott and Emma Paradine essentially run away from home-run joyfully, enthusiastically away from everything they or (more importantly) their parents have ever known. Their parents are left behind, broken-hearted and bewildered; there is no indication that Scott or Emma feels the slightest pang of remorse; there is very little reason to hope that their parents will ever see them again. $^{22}$ In Bob Shaye's movie The Last Mimzy, the Wilders are a family visibly troubled by the stresses common to many families in these modern times; but Noah and Emma Wilder love their parents (although, as a reflection of those above-mentioned stresses, Noah occasionally expresses irritation to/at his father) and exhibit no desire to leave them. ${ }^{23}$ Towards the end of the movie, Emma is trapped in the field of force designed to return Mimzy to its point of origin, far in the future; she is rescued by the concerted, loving action of her parents and her brother, and in the end the Wilders are a stronger family as a result of the trials they have withstood together.

Speculative-fiction stories in print sometimes involve the wrenching-apart of families, in many cases focussing on the differing perspectives of different generations and the assumption that children are more flexible or malleable than adults, including their parents. But major movies are (necessarily, for economic reasons) aimed at a broader audience, and especially if they are based on speculative-fiction stories and therefore include characters, props, and/or concepts that are significantly out of the ordinary, in order to nevertheless be maximally comfortable (and comforting) to such an audience typically include as a theme the reinforcing and reassertion of family ties. As shown in this paper, this is one of the changes typically made in the adaptation of a speculative-fiction story from a print-source to the screen.

\footnotetext{
${ }^{22}$ Scott's comments with regard to the salmon life-cycle carry some hint of the possibility that he and Emma will someday return to their original environment. But salmon only do this at the very end of their lives; if Scott and/or Emma should follow this example, their parents will probably be long since dead.

${ }^{23}$ Cf. Emma’s statement to Mimzy: “I don't want the world to end. Ever. I love the world. ...I know ... i know ... with all my heart”. Shaye's Emma has no wish to leave her parents or the world; instead, she does all in her power to save the world.
} 


\section{References}

Canton, M. (Producer), \& Waters, M. (Director). (2007). The Spiderwick chronicles [motion picture]. Hollywood: Paramount/Nickelodeon.

Clarke, A. C. (1953). Childhood's end. New York: Del Ray.

Cooper, S. (1973). The dark is rising. New York: Aladdin.

DiTerlizzi, T., \& Black, H. (2003-2004). The Spiderwick chronicles. New York: Simon and Schuster.

Padgett, L. (1943). Mimsy Were the Borogoves. In R. Silverberg (Ed., 1970), The science fiction hall of fame (Vol. I) (pp. 226-260). New York: Avon.

Phillips, M. (Producer), \& Shaye, B. (Director). (2007). The last Mimzy [motion picture]. Los Angeles: New Line Cinema.

Platt, M. (Producer), \& Cunningham, D. (Director). (2007). The seeker: The dark is rising [motion picture]. Los Angeles: 20th Century Fox/Walden.

Spielberg, S. \& Kennedy, K. (Producers), \& Spielberg, S. (Director). (1982). E. T.: The extraterrestrial [motion picture]. Los Angeles: Universal/Amblin. 